\title{
Alternative techniques improve irrigation and nutrient management on dairies
}

\author{
Larry Schwankl \\ Carol Frate \\ $\nabla$
}

\begin{abstract}
Many of the dairies in California's
\end{abstract}
Central Valley use a water flush sys-

tem for manure handling; the manure water is eventually mixed with freshwater and applied to cropland during irrigation. Good performance during irrigation applications is important due to the nutrients in the manure water. This project evaluated alternative management techniques (furrow torpedoes, surge irrigation and shortening furrow lengths) for improving irrigation practices on dairies. All three techniques reduced the amount of water required for irrigation. The project also investigated the impact of changing the timing of manurewater additions to the fresh irrigation water. Delaying the addition of manure water until the advancing fresh irrigation water had reached approximately $80 \%$ of the distance down the field improved nutrientapplication uniformity and reduced nutrient applications.

M any of the more than 1,600 dairies in the Central Valley of California use a water flush system to clean manure from free-stall barns. This flush water is collected and held in ponds until it can be mixed with freshwater and applied to cropland as part of surface irrigation practices. The application of manure-water nutrients in excess of agronomically appropriate rates can result in loss of nutrients, often to deep percolation below the crop's root zone. Due to the high levels of nutrients in manure water, high efficiency and uniformity are important to assure a uniform distribution of nutrients during irrigation and

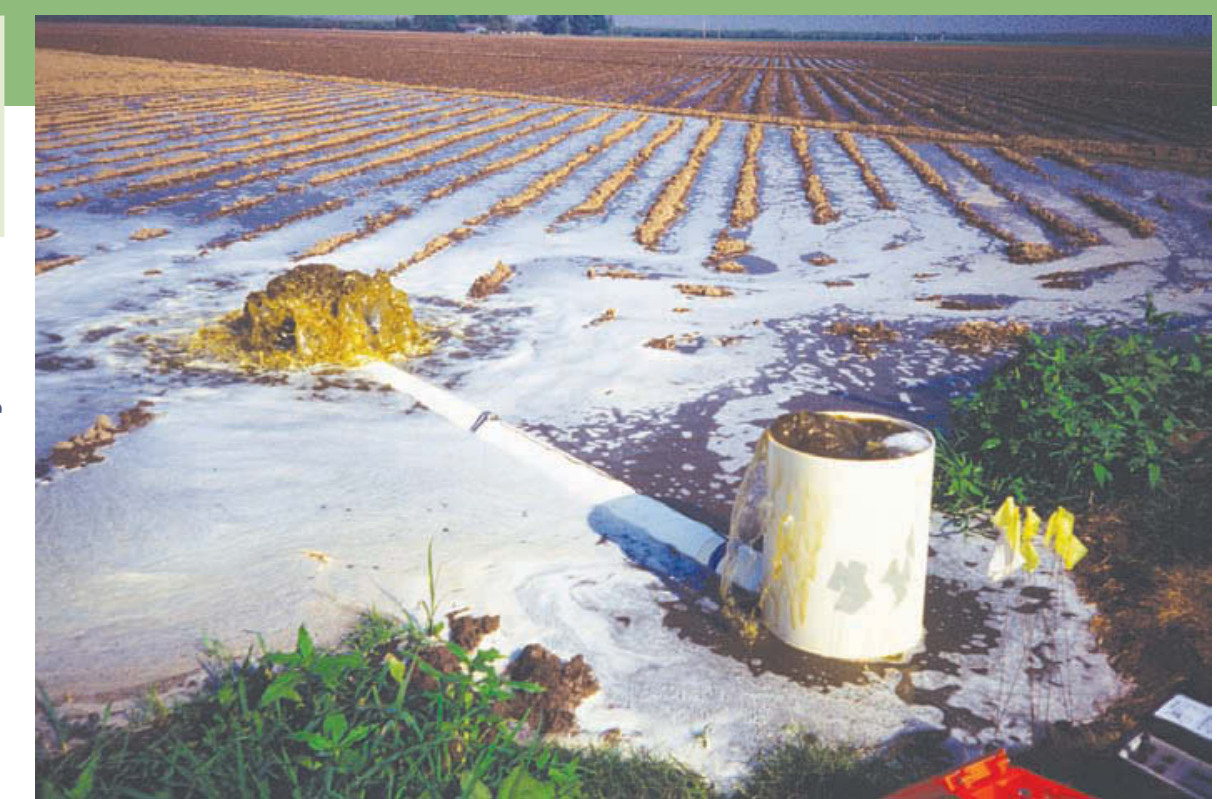

Researchers measured water discharge into the field by placing plastic hydrants over alfalfa valves with a Doppler flow meter attached.

to minimize the deep percolation of nitrates, which can pollute groundwater.

Furrow and border irrigation systems are commonly used with manurewater applications on dairies in the San Joaquin Valley. Sprinkler irrigation with manure water is seldom used due to odor and air pollution concerns, and is prohibited in some counties. Furrow and border irrigation systems are often inefficient due to over-irrigation and poor application uniformity. Tailwater - irrigation water that runs off the end of a field - that is not reused is one source of inefficiency. Tailwater containing manure cannot leave the grower's property, and the standard practice on dairies is to minimize its generation during irrigation. If tailwater is generated, a return system is often used to collect it for reuse.

Deep percolation is the major contributor to irrigation inefficiency on dairies, and over-irrigation often results when fields are too long. A certain quantity of irrigation water is required simply to advance water to the end of the field. This is the minimum amount of water applied per irrigation event, which often exceeds the amount of water required to refill the crop's root zone and results in inefficient irrigation.

A field project was undertaken during the summers of 2001 and 2002 to evaluate techniques for improving the irrigation and nutrient management of flood irrigation systems that apply manure water. Improved irrigation systems should apply water and the nutrients carried in water (water-run) more evenly on the field and allow application of the correct amount of water to match crop needs. Three irrigation-water management techniques - furrow torpedoes, surge irrigation and field-length reductions - were investigated on a Tulare County dairy. Another management strategy, manipulating the timing of manurewater additions to the fresh irrigation water, was evaluated on the same dairy.

\section{Furrow torpedoes}

Furrow torpedoes are steel cylinders, often filled with concrete, which are dragged in the furrow to break up soil clods and smooth the surface. They can allow water to advance across a field more quickly, resulting in improved irrigation uniformity and efficiency. Torpedo use is beneficial after field preparation or cultivation, but it is not 


\section{The application of manure-water nutrients in excess of agronomically appropriate rates can result in loss of nutrients, often to deep percolation below the crop's root zone.}

effective if there is no cultivation to disturb the furrow between irrigations (Schwankl et al. 1992).

The impact of torpedo use for manure-water irrigations was evaluated by comparing three irrigation blocks of 25 torpedoed furrows each, with the same number of blocks and furrows that were not torpedoed. All furrows were 1,250 feet long. Water was supplied at the head of the field using an underground pipeline with alfalfa valves. Each block of 25 furrows - centered on an alfalfa valve - was bordered by berms running the length of the field. These berms kept the water from each alfalfa valve constrained to flow down the 25 furrows supplied by that valve. This is a common irrigation system for dairies in the San Joaquin Valley.

The preseason irrigation event was monitored. This irrigation is often inefficient because the soil has been extensively worked and has a high infiltration rate. A PVC hydrant with a discharge pipe out its side was placed over the alfalfa valve during irrigation. A Doppler flow meter was attached to the hydrant's discharge pipe to measure the flow rate and volume applied to each monitored block of furrows. The flow rates from the valves supplying areas being compared were kept as similar as possible, and records of total volume applied versus irrigation time were collected. There was some variation in inflow between furrows being

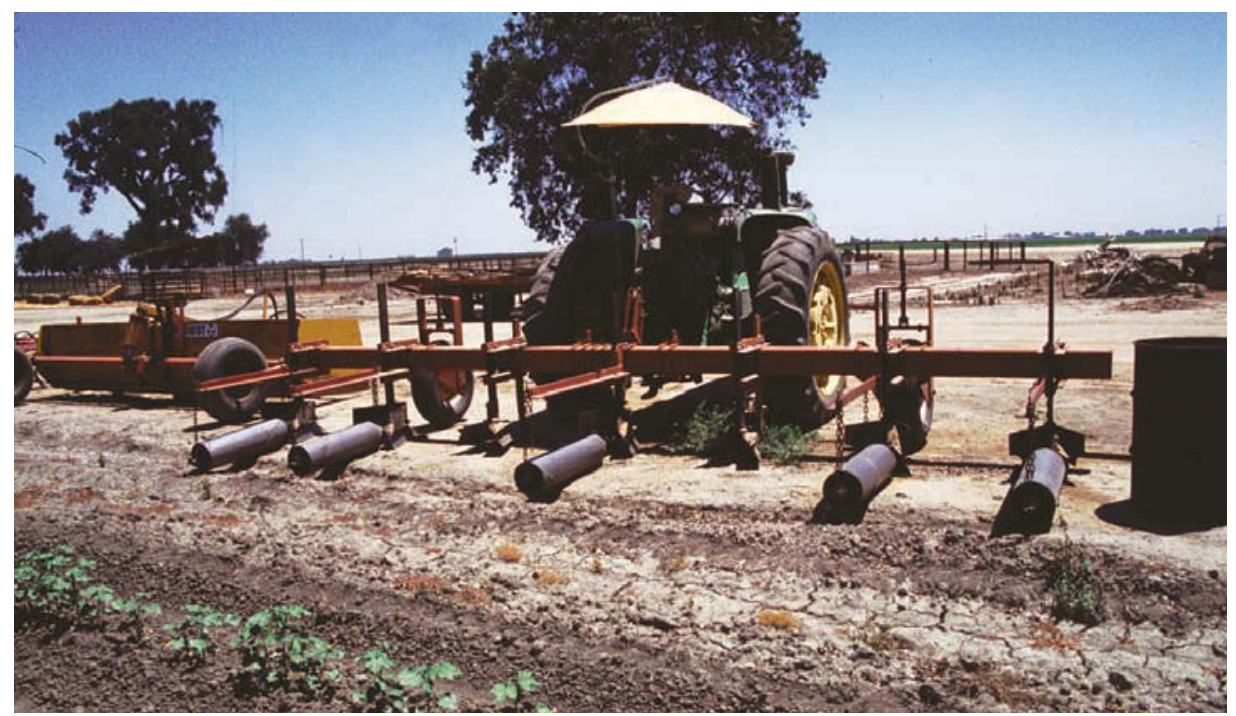

Furrow torpedoes are attached to a sled to ease turning at the end of the field.

supplied by a common alfalfa valve, but the water advance was fairly consistent between furrows. The rate that water advanced along the furrow was also monitored. Information on the advance rate and irrigation set-time was used to determine the intake opportunity times and the infiltrated water at locations within the field.

The irrigation set was changed soon after water reached the end of the field. Without a return system, care was taken to minimize tailwater runoff. Tailwater generated by furrows - in which water advanced faster to the end of the field - flowed a short distance into the tail end of "dry" furrows, which had not yet completed their water advance. Torpedo use was effective in reducing the applied water from 12.9 to 9.4 inches - a $27 \%$ reduction from continuous-flow irrigation (table 1). Water advanced faster across the field, resulting in a shorter irrigation set-time and less water applied. Torpedo use is not widespread in the San Joaquin Valley, primarily due to the difficulty and cost. The torpedoes are dragged behind a tractor and it is often difficult to turn at the end of the field with the torpedoes attached. Some growers have solved this problem by connecting the torpedoes to a sled so that they can be hydraulically lifted at the ends of fields. Because of these complications, furrows are often torpedoed as a separate equipment pass through the field - an added cost.

\section{Surge irrigation on dairies}

Surge irrigation is the on-off cycling of water during irrigation. Water is allowed to run down a group of furrows and at some point (such as one-quarter of the way down the field), the water is moved to another group of furrows. While water is running in the second group of furrows, water in the first group of furrows is infiltrating and the furrows are "de-watering." When water in the second group of furrows has advanced to the same distance as the first group, water is switched back to the first group. As water is reintroduced to the first group of furrows, it advances across the wetted portion of the field very quickly and then slows down appreciably as it starts to advance across the dry soil. This on-off cycling of water is continued until water reaches the end of the field.

This practice can improve irrigation efficiency by advancing water across the field using less water - as compared to continuous-flow irrigation - due to an infiltration reduction on soil wetted by a previous surge cycle (Hanson et al. 1998). This infiltration-rate reduction is likely due to a sealing of the soil surface. Surge irrigation has not been previously investigated on fields irrigated with manure water. Manure water contains a substantial amount of fine solids, which was thought to have a significant positive impact on surge-irrigation performance.

Surge irrigation was evaluated by comparing two blocks of 25 furrows each irrigated with continuous flow; and four blocks of 25 furrows each surge-irrigated. Four surge cycles were used. Water was allowed to advance about one-quarter of the way down the field (300 feet), and then the water was transferred to another section of furrows. By the time the water was transferred back to the original section, water had infiltrated into the furrow. During the second surge, water was allowed to advance another one-quarter of the field (to 600 feet). Water was again transferred to another set of furrows. This continued for the third surge (advance to 900 feet) and fourth surge (advance to the end of the field $-1,250 \mathrm{feet}$ ). 


\begin{tabular}{|c|c|c|c|c|}
\hline \multirow[b]{2}{*}{ Block } & \multirow[b]{2}{*}{ Torpedoed } & \multirow[b]{2}{*}{ Flow } & \multicolumn{2}{|c|}{ Applied water } \\
\hline & & & \multicolumn{2}{|c|}{ at $1,250 \mathrm{ft}$. at $600 \mathrm{ft}$. } \\
\hline & & & \multicolumn{2}{|c|}{$\ldots .$. inches. ..... } \\
\hline 1 & No & Continuous & 12.9 & 7.1 \\
\hline 2 & No & Surge & 9.1 & 5.4 \\
\hline 3 & No & Surge & 8.4 & 5.2 \\
\hline 4 & Yes & Surge & 7.8 & 5.0 \\
\hline 5 & Yes & Surge & 10.5 & 4.8 \\
\hline 6 & Yes & Continuous & 9.4 & 4.3 \\
\hline
\end{tabular}

Surge irrigation was effective in reducing the amount of water required to irrigate nontorpedoed furrows. Applied water was reduced from 12.9 to 9.1 inches - a $30 \%$ decrease, or from 12.9 to 8.4 inches - a 35\% decrease (table 1). For torpedoed furrows that were surgeirrigated, results were mixed. Applied water on one section of furrows was reduced from 9.4 to 7.8 inches - a $17 \%$ decrease (table 1). On another block of 25 furrows, the torpedoed/surgeirrigated furrows required more water, 9.4 versus 10.5 inches - a $12 \%$ increase (table 1). Surveying the field slope on the monitored blocks revealed that block 5 had an uneven slope, which likely affected the amount of applied water required. From these results, it is not conclusive that using surge irrigation on torpedoed furrows is beneficial. It is likely that the excess applied water avoided by using surge irrigation or torpedoes would go to deep percolation, which could leach nitrates.

Surge irrigation would therefore seem to be a natural practice for growers to adopt, but the furrow systems on most dairies do not lend themselves to it. Surge irrigation using freshwater alone is done using gated pipe and an automatic surge valve. Dairies seldom use gated pipe because the manure solids and trash (such as weeds and baling twine) in the manure water clog the discharge openings. Instead, dairies often use alfalfa valves, which discharge water into a block of furrows. An added complication is that the automatic surge valve has an internal, motorized, butterfly valve that could become entangled with trash in the water. To use surge irrigation on dairies now would require irrigators to manually open and close alfalfa valves - a significant increase in labor and management costs.

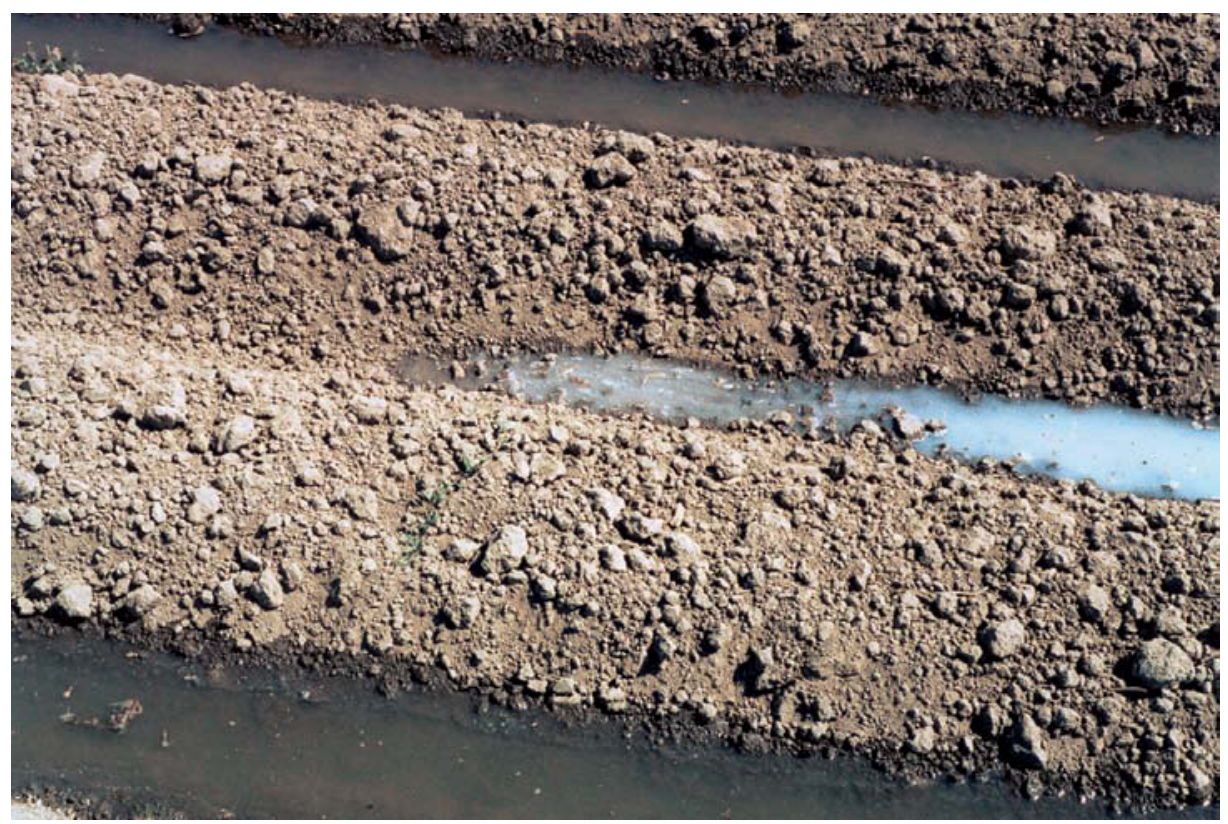

Sulfur fertilizer has been added to this advancing front of water, to act as a visual tracer. The tracer has not been added to water in the furrows at the top and bottom

Irrigations occur day and night. Using surge irrigation at night is more complicated than during the day, when advance rates can be more easily observed. However, once an irrigator determines the advance times on a field, surge-irrigation switches could be made on an irrigation-time basis. This assumes a constant irrigation flow-rate to each block of a field, which can be difficult to achieve since many ranches irrigate multiple fields at the same time.

\section{Reducing field lengths}

San Joaquin Valley field lengths vary widely, but one-quarter mile is common. This is often too long to allow water applications that match the water needs of the crop. The minimum irrigation-application amount is determined by the amount of water needed to advance water to the end of the field. For example, if 6 inches of water is required but the crop water use since the last irrigation has been 4 inches, at least 2 inches of water would be lost to deep percolation (assuming no tailwater runoff). If nutrients are available to be leached, the excess water could be the vehicle for carrying them below the crop's root zone. Shortening the field length allows a lesser irrigation amount to be applied during an irrigation set and allows that amount to more closely match the water depleted from the crop's root zone, thereby increasing irrigation efficiency. Irrigation uniformity is also improved in shorter fields.
Evaluation of irrigation-system performance for shorter field lengths was relatively simple since the applied water, advance time and other necessary information was available as a subset of the field-evaluation data that was collected as part of the continuous/surge flow evaluations. The 1,250-foot furrows were evaluated to see how much water would be required if field length was reduced to 600 feet (table 1). Applied irrigation amounts could be reduced by $35 \%$ to $55 \%$ when field lengths were reduced from 1,250 to 600 feet.

Reductions in field length have the greatest impact on irrigation performance, but they are also the most costly and inconvenient to implement. To reduce a one-quarter-mile-long field to two one-eighth-mile fields would require a new pipeline ( $\$ 15,000$ to $\$ 20,000$ for a 40 -acre field), a new road (a capital cost and land lost from production) and possibly new tailwater-collection facilities. Shorter field lengths are also a significant inconvenience when equipment is moved through the field, with consequent impacts on field preparation, cultivation, pest and weed control, and harvest activities.

\section{Timing of manure-water additions}

Field tests were done to manipulate the timing of manure-water additions to irrigation water. The objectives were: (1) to improve the uniformity of nutrient applications, and (2) to provide a 
(furrow-irrigated, 1,200 ft. long)

method for applying smaller amounts of nutrients per irrigation event as compared to adding manure water during the entire irrigation event, which is currently the most common practice. This strategy of changing the timing of manure-water additions hinges on infiltration characteristics, which vary during irrigation. The infiltration rate is high when water first comes into contact with a dry soil and then decreases, often significantly, until a final, relatively constant intake rate is reached. Due to the time required for water to advance across the field, water is in contact with the soil (intake opportunity time) at the head of the field for a significantly greater time than at the field's tail end. The result is more infiltrated water at the head of the field than the tail. The same is true of nutrient applications if manure water is added continuously to the irrigation water.

To apply a lower nutrient amount during a continuous irrigation by using manure water with a high nitrogen concentration, a smaller flow-rate of manure water must be added to the irrigation water. This is often incompatible with the large manure pumps and pipelines designed for high flow-rates that dairies currently have. Running small flow-rates of manure water through large pipelines can result in settling and clogging of the pipeline.

We evaluated multiple irrigation events at the Tulare County commercial dairy. For an initial visual evaluation, a tracer (sulfur fertilizer) was added to the irrigation water at various delayed times during the irrigation event. The sulfur fertilizer turns the irrigation water milky in appearance and can be visually tracked as it moves down the furrow. The sulfur fertilizer was not used to trace infiltrated nutrients into the soil profile. From monitoring the tracer, it became evident that nutrient additions to the irrigation water could begin quite late in the irrigation set and still have time to advance to the end of the field before the end of the irrigation set.

From these tracer tests, we determined that the addition of manure water would start when clean irrigation water had advanced approximately 900 feet along the 1,250-foot-long field.

\begin{tabular}{|c|c|c|c|c|c|}
\hline $\begin{array}{l}\text { Nutrient application } \\
\text { strategy }\end{array}$ & $\begin{array}{l}\text { Average } \\
\text { irrigation }\end{array}$ & $\begin{array}{c}\text { Irrigation } \\
\text { uniformity (DU) }\end{array}$ & $\begin{array}{c}\text { Avg. manure } \\
\text { water infiltrated }\end{array}$ & $\begin{array}{l}\text { Manure-water } \\
\text { uniformity (DU) }\end{array}$ & $\begin{array}{c}\text { Nitrogen } \\
\text { applied }\end{array}$ \\
\hline & inches & $\%$ & inches & $\%$ & Ib/ac \\
\hline $\begin{array}{l}\text { Manure water added } \\
\text { during entire irrigation }\end{array}$ & 7.1 & 64 & 7.1 & 64 & 242 \\
\hline $\begin{array}{l}\text { Manure water started } \\
\text { when freshwater advance } \\
=900 \mathrm{ft} . ; \text { shut-off when } \\
\text { advanced to end of field }\end{array}$ & 7.1 & 64 & 2.5 & 69 & 86 \\
\hline $\begin{array}{l}\text { Simulation } 1 \\
\text { Manure water started } \\
\text { when freshwater advance } \\
=900 \mathrm{ft} \text {; shut-off }=\text { end of } \\
\text { field advance }+1 \mathrm{hr} .\end{array}$ & 7.6 & 70 & 3.0 & 69 & 102 \\
\hline $\begin{array}{l}\text { Simulation } 2 \\
\text { Manure water started } \\
\text { when freshwater advance } \\
=1,000 \mathrm{ft} \text {.; shut-off when } \\
\text { advanced to end of field }\end{array}$ & 7.1 & 64 & 0.9 & 91 & 31 \\
\hline $\begin{array}{l}\text { Simulation } 3 \\
\text { Manure water started } \\
\text { when freshwater advance } \\
=1,000 \mathrm{ft} \text {; shut-off }=\text { end of } \\
\text { field advance }+1 \mathrm{hr} \text {. }\end{array}$ & 7.6 & 70 & 1.4 & 88 & 49 \\
\hline
\end{tabular}

As a result, the advancing front of the manure-water/freshwater mix caught the advancing front of the freshwater at the 1,050-foot furrow distance. It took the clean irrigation water 4 to 5 hours to advance to 1,050 feet, but it took the delayed manure-water advancing front less than 1 hour to reach the 1,050-foot mark.

Water samples were collected at frequent intervals (such as 15 minutes, but sometimes modified to more accurately measure water-quality changes) and at multiple locations along the furrow. These water samples traced the movement of the manure water along the furrow and provided the spatial and temporal distribution of water quality during the irrigation event.

RBC flumes were placed in furrows to monitor furrow flow-rate. The field was surveyed and its slope was determined. Advance-recession measurements were also gathered. The results from the irrigation evaluation were used to provide inputs to a two-point Volume Balance furrow-irrigation model (Walker and Skogerboe 1987), to determine infiltrated water amounts along the furrow and the irrigation uniformity.

The results of delaying additions of manure water to the irrigation water were promising: not only could a lesser amount of nutrient be applied using the existing manure-water application equipment, but the nutrients could also be applied more uniformly.

\section{Water quality}

Nitrogen and ammonium are found in manure water and can pollute groundwater if applied at levels too high and then leached through the soil profile. The fresh irrigation water/ manure-water mix used for irrigation had approximately 100 milligrams per liter (mg/l) ammonium $\left(\mathrm{NH}_{4}-\mathrm{N}\right)$ and $150 \mathrm{mg} / 1$ total nitrogen. For example, nitrogen samples taken 30 minutes after manure water traveled 900 feet along the field recorded the following ammonium $(\mathrm{mg} / \mathrm{l})$ and total nitrogen (mg/l) levels: head of field, 101 and 155; 300 feet along field, 106 and 155; 600 feet along field, 107 and 131; and 900 feet along field, 101 and 139. There was little change in ammonium content and a slight change in total nitrogen of the water along the furrow. As is common with dairy manure-waters, there was no nitrate in the manure water because manure ponds are anaerobic (oxygenfree). The manure water used for irrigation was relatively low in solids since the dairy had a solids separator and a multipond manure-handling system.

For this manure water, the majority of the nitrogen nutrients were tied up in the ammonium form and in the organic form as small particles that stay 
in suspension. The constant nitrogen content of the irrigation water along the furrow may not hold for manure water high in large particles, which settle out at the head of the field. In such cases, it is possible that the organic nitrogen content of the water would decrease more significantly as it moves down the furrow.

\section{Infiltration, irrigation uniformity}

In order to gauge infiltration and irrigation uniformity, we monitored an early-season irrigation event following a cultivation. Water advanced across the field in approximately 5.5 hours. The average irrigation depth applied was 7.1 inches with a distribution uniformity (DU) of 64\% (table 2). As with many dairies in Tulare County, the irrigation system was operated to minimize tailwater runoff. Therefore, once water advanced to the end of the field, it was allowed to run only a short time before the irrigation set was switched. As a result, the top end of the field received substantially more infiltrated water than the tail end. For the monitored irrigation event, the head of the field received approximately 9.4 inches of infiltrated water while the tail end received approximately 3.1 inches.

If manure water had been added to the irrigation flows during the entire irrigation event, the uniformity of nitrogen application would have been the same as the water application uniformity $-64 \%$. The top end of the field would have received significantly more nitrogen than the tail end. Adding manure water during the entire irrigation event would have resulted in the field receiving an average of 242 pounds of nitrogen per acre, which is generally considered to be excessive for a single irrigation event (table 2).

When manure water was added to the irrigation water after freshwater had advanced 900 feet along the furrow, the manure-water application uniformity was increased from $64 \%$ to $69 \%$. However, at least as importantly, the average nitrogen application to the field was reduced from 242 to 86 pounds per acre (table 2), a level more appropriate for nutrient management.

With the field data available for model verification, the following simulations of other irrigation and manure-timing strategies were investigated using a two-point Volume Balance model.

Simulation 1. Manure-water additions began when freshwater reached 900 feet along the furrow. Irrigation water was shut off 1 hour after it reached the end of the field. This strategy would result in a nutrient application uniformity nearly the same as the irrigation uniformity $(69 \%$ versus $70 \%$ )(table 2$)$, but the average nitrogen application amount is reduced from 242 pounds per acre for the continuous manure-water addition strategy to 102 pounds per acre for this delayed manure-water addition practice.

Simulation 2. Freshwater was allowed to advance 1,000 feet along the furrow before manure water was added to the irrigation water. The irrigation supply was shut off shortly after water reached the end of the field. The result of this practice would be a small amount of nitrogen (31 pounds per acre) applied to the field very uniformly (DU $=91 \%$ ). This is a good strategy if frequent, small applications of nitrogen are desired.

Simulation 3. In this delayed manurewater addition strategy, manure water was added to the irrigation water after freshwater had advanced to 1,000 feet. Irrigation was allowed to continue for 1 hour after water advanced to the end of the field. This strategy allows the application of a limited amount of nitrogen to the field (49 pounds per acre) while applying it with a high uniformity $(88 \%)$. Of all the strategies evaluated, this is preferable since it increases both the irrigation and nutrient application uniformities (table 2) compared to adding manure water during the entire irrigation event, which is stopped when water reaches the end of the field.

Delayed addition of manure water holds promise as a means of improving nutrient application uniformity and of applying less nitrogen during an irrigation, while still using existing highflow-rate manure-water pumps and pipelines. One disadvantage of delaying manure-water applications is that there is a delay between when manure-water pumps are turned on and when manure water reaches the irrigated field. For the field evaluated in this study, that delay was approximately 20 minutes. Furthermore, it is quite common for dairies to irrigate multiple fields at the same time, often at different locations on the dairy and utilizing complex piping systems, to deliver the water. This makes delayed manure-water additions, as well as any form of manure-water nutrient management, a complex task.

\section{Reducing applied irrigation water}

The three irrigation water-management techniques - furrow torpedoes, surge irrigation and shortening field lengths - were all effective in reducing the amount of applied water per irrigation. Furrow torpedoes reduced the applied water by approximately $25 \%$ and surge irrigation by $15 \%$ to $35 \%$. Field-length reductions were also effective. Splitting a one-quarter-mile field into two oneeighth-mile fields could reduce the applied irrigation water by $35 \%$ to $55 \%$.

The normal practice for applying manure water to a field is to add it to the freshwater during the entire irrigation event. Delaying addition of manure water until the advancing freshwater has reached 900 feet along a 1,250-foot field resulted in an increase in distribution uniformity (64\% vs. $69 \%$ ) of the manurewater application and a decrease in applied nitrogen (242 versus 86 pounds per acre) as compared to the continuous addition of manure water. Simulation of other delayed manure-water addition strategies indicated that nutrient application uniformity could be increased to nearly $90 \%$ while applying 30 to 50 pounds per acre of nitrogen during an irrigation event.

\section{Schwankl is Irrigation Specialist, UC Cooperative Extension, UC Davis; and C. Frate is Farm Advisor, UC Cooperative Extension, Tulare County. The authors would like to thank the UC Center for Wa- ter Resources-Prosser Trust Fund for sup- port of this work.}

\section{References}

Hanson B, Schwankl L, Bendixon W, Schulbach K. 1998. Surge Irrigation. UC DANR Communications Services Pub 3380. 48 p. Schwankl LJ, Hanson BR, Panoris S. 1992. Torpedoing the irrigation advance problem. Cal Ag 46(6):15-7.

Walker WR, Skogerboe GV. 1987. Surface Irrigation: Theory and Practice. Englewood Cliffs, NJ: Prentice Hall. 386 p. 